\title{
Short communication: Evaluation of the microbiota of kefir samples using metagenetic analysis targeting the 165 and $26 S$ ribosomal DNA fragments
}

\author{
N. Korsak, ${ }^{* 1}$ B. Taminiau, ${ }^{*}$ M. Leclercq, ${ }^{*}$ C. Nezer, $†$ S. Crevecoeur, ${ }^{*}$ C. Ferauche,† E. Detry, $†$ V. Delcenserie, ${ }^{*}$ \\ and G. Daube* \\ ${ }^{*}$ Fundamental and Applied Research for Animal \& Health (FARAH), Food Science Department, Faculty of Veterinary Medicine, \\ University of Liège, Sart-Tilman, B43b Liège, B-4000 Belgium \\ †Quality Partner S.A., Rue Hayeneux, 624040 Herstal, Belgium
}

\section{ABSTRACT}

Milk kefir is produced by fermenting milk in the presence of kefir grains. This beverage has several benefits for human health. The aim of this experiment was to analyze 5 kefir grains (and their products) using a targeted metagenetic approach. Of the 5 kefir grains analyzed, 1 was purchased in a supermarket, 2 were provided by the Ministry of Agriculture (Namur, Belgium), and 2 were provided by individuals. The metagenetic approach targeted the V1-V3 fragment of the $16 \mathrm{~S}$ ribosomal (r)DNA for the grains and the resulting beverages at 2 levels of grain incorporation (5 and 10\%) to identify the bacterial species population. In contrast, the $26 \mathrm{~S}$ rDNA pyrosequencing was performed only on kefir grains with the aim of assessing the yeast populations. In parallel, $\mathrm{pH}$ measurements were performed on the kefir obtained from the kefir grains using 2 incorporation rates. Regarding the bacterial population, $16 \mathrm{~S}$ pyrosequencing revealed the presence of 20 main bacterial species, with a dominance of the following: Lactobacillus kefiranofaciens, Lactococcus lactis ssp. cremoris, Gluconobacter frateurii, Lactobacillus kefiri, Acetobacter orientalis, and Acetobacter lovaniensis. An important difference was noticed between the kefir samples: kefir grain purchased from a supermarket (sample E) harbored a much higher proportion of several operational taxonomic units of Lactococcus lactis and Leuconostoc mesenteroides. This sample of grain was macroscopically different from the others in terms of size, apparent cohesion of the grains, structure, and texture, probably associated with a lower level of Lactobacillus kefiranofaciens. The kefir (at an incorporation rate of $5 \%$ ) produced from this sample of grain was characterized by a lower $\mathrm{pH}$ value (4.5) than the others. The other 4 samples of kefir $(5 \%)$ had $\mathrm{pH}$ values above 5 . Comparing the kefir grain and the kefir, an increase

Received November 4, 2014.

Accepted February 16, 2015.

${ }^{1}$ Corresponding author: nkorsak@ulg.ac.be in the population of Gluconobacter in grain sample B was observed. This was also the case for Acetobacter orientalis in sample D. In relation to $26 \mathrm{~S}$ pyrosequencing, our study revealed the presence of 3 main yeast species: Naumovozyma spp., Kluyveromyces marxianus, and Kazachastania khefir. For Naumovozyma, further studies are needed to assess the isolation of new species. In conclusion, this study has proved that it is possible to establish the patterns of bacterial and yeast composition of kefir and kefir grain. This was only achieved with the use of high-throughput sequencing techniques. Key words: kefir, microbiota, metagenetics, $16 \mathrm{~S}$ rRNA sequencing, 26S rRNA sequencing

\section{Short Communication}

Originally from the Caucasus Mountains (Otles and Cagindi, 2003), kefir is widely consumed in Eastern Europe but now encountered all over the world. The word "kefir" means "good feeling" in Turkish, due to the cooling nature of this beverage. The kefir beverage is produced by mixing milk, water, or fruit juice with kefir grains, which have the appearance of small cauliflowers (Lopitz-Otsoa et al., 2006). These grains are a symbiotic combination of bacteria (mainly lactobacilli) and yeast that are protected by an exopolysaccharide structure called kefiran, which is mainly produced by Lactobacillus kefiranofaciens in conjunction with yeasts (Lopitz-Otsoa et al., 2006; Hamet et al., 2013). More precisely, the Codex Alimentarius commission states that kefir is a combination of bacteria belonging to several genera (Lactobacilli, Leuconostoc, Lactococcus, and Acetobacter) and yeasts. The latter may belong to a group that ferment lactose (such as Kluyveromyces marxianus) or not (e.g., Saccharomyces; Codex Alimentarius, 2003). Bacteria in the starter culture have to be present at a level of $10^{7} \mathrm{cfu} / \mathrm{g}$, whereas yeast must be present at a level of $10^{4} \mathrm{cfu} / \mathrm{g}$.

In the case of kefir derived from milk, its production consists of mixing milk (whole or skim milk) with kefir grains at an inoculation rate of 5 to $10 \%$. This inocula- 
tion rate can influence the organoleptic characteristics of the final product. The fermentation starts after mixing and lasts for a period of $24 \mathrm{~h}$ at temperatures of 20 to $25^{\circ} \mathrm{C}$ (Kök-Taş et al., 2013).

Regarding the health benefits of kefir, several experiments conducted on mice in vitro and have led to the following suspected effects: improvement of intestinal microbiota (prebiotic or probiotic effect), regression of tumors, promotion of skin healing, decrease of lowdensity lipoprotein cholesterol, improving of immunity, and reduction of clinical signs due to lactose intolerance, among other things (Hertzler and Clancy, 2003; Rodrigues et al., 2005; de Moreno de Leblanc et al., 2007; Guzel-Seydim et al., 2011; Zheng et al., 2013). Several positive effects against food-borne pathogens have also been observed in vitro and in vivo (Santos et al., 2003; Golowczyc et al., 2008; Chen et al., 2013). In Europe, all these positive effects on health need to be confirmed and validated by the European Food Safety Authority to make any health claims.

The aim of our experiments was to assess, using pyrosequencing, the microbial composition (bacteria and yeasts) of kefir grains and kefir obtained after mixing whole milk and grains and $24 \mathrm{~h}$ of fermentation. In addition, we compared 5 different samples of kefir, 1 of which had been purchased from a supermarket. Throughout, the term "kefir" is used to denote the beverage obtained after the fermentation process.

Five samples of kefir grains were obtained: 2 from individuals (A, B), 2 from the Ministry of Agriculture in Namur (Belgium; C, D), and 1 purchased from a Belgian supermarket (E). The 2 rates of inoculation were tested ( 5 and 10\%) for preparation of kefir, which was done by mixing the grains with whole milk. For this purpose, a weight with a precision of $0.1 \mathrm{~g}$ was used (Sartorius Basic, Merck Eurolab Calibrated 6/2002; Sartorius, Palaiseau, France). The kefir grains and kefir mixtures were incubated at $25^{\circ} \mathrm{C}$ for $24 \mathrm{~h}$.

The $\mathrm{pH}$ of the kefir was measured after $24 \mathrm{~h}$ of fermentation using a $\mathrm{pH}$ meter equipped with a penetration probe and a temperature probe $(\mathrm{pH}$-meter 656 Calimatic, Knick Elektronische Mebgeräte, Berlin, Germany). The results are shown in Table 1. The lowest $\mathrm{pH}$ values were obtained for kefir $\mathrm{E}$. The $\mathrm{pH}$ values were also lower for kefir obtained at an incorporation rate of $10 \%$ compared with those obtained at $5 \%$.

To establish the bacterial and yeast composition, the 5 grains and 10 kefir samples produced were analyzed using targeted metagenetics analysis. Before analysis, the 15 samples were kept at $-24^{\circ} \mathrm{C}$ for 2 mo. Total DNA was extracted using an extraction kit, following the manufacturer's instructions (DNeasy Blood and Tissue DNA extraction kit, Qiagen, Venlo, the Netherlands).
The bacterial V1-V3 regions of the $16 \mathrm{~S}$ rRNA gene were amplified by PCR using a pair of degenerate primers designed in this study and leading to an amplicon of $625 \mathrm{bp}$. For yeast, the D1/D2 region of the $26 \mathrm{~S}$ rRNA gene was specifically amplified. This pyrosequencing was performed only on the grains (Kurtzman and Robnett, 1997).

For the GS Junior Titanium (Roche, Mannheim, Germany) chemistry, the following forward primer was used: 5'-CCTATCCCCTGTGTGCCTTGGCAGTCTCAGGAGAGTTTGATCATGGCTCAG-3' containing the $\mathrm{B}$ adaptor, a key sequence (TCAG), and a broadly conserved bacterial primer (Roche, Basel, Switzerland). A reverse primer was also used ( 5 '-CCATCTCATCCCTGCGTGTCTCCGACTCAGNNNNNNNNNTACCGCGGCTGCTGGCAC-3'); it contained the A adaptor, a key sequence (TCAG), 8 base barcodes to distinguish the samples, and a broadly conserved bacterial primer.

The PCR conditions were $4 \mathrm{~min}$ at $94^{\circ} \mathrm{C}, 25$ cycles of denaturation $\left(15 \mathrm{~s}\right.$ at $\left.94^{\circ} \mathrm{C}\right)$, annealing $\left(45 \mathrm{~s}\right.$ at $\left.56^{\circ} \mathrm{C}\right)$, and extension $\left(60 \mathrm{~s}\right.$ at $\left.72^{\circ} \mathrm{C}\right)$, followed by a final elongation $\left(8 \mathrm{~min}\right.$ at $\left.72^{\circ} \mathrm{C}\right)$. The PCR products of 625 nucleotides were checked by gel electrophoresis and purified using the AMPure Kit (Agencourt Bioscience Corporation, Beverly, MA) to remove amplicons shorter than 100 bp. Equal amounts of each PCR product were pooled and subsequently amplified by emulsion PCR before sequencing. Pyrosequencing was performed with the Roche 454 GS Junior Sequencer (Roche) using the massively parallel pyrosequencing protocol (Margulies et al., 2005). For bioinformatics analysis, image and data processing for amplicon sequencing were performed using the Genome Sequencer FLX System Software Package 2.3 (Roche). The sequences were preclustered to reduce false operational taxonomic units (OTU) produced by erroneous sequences. A distance matrix was prepared (distance $=0.03$ ) and the sequences were clustered to OTU using the average neighbor algorithm. An $80 \%$ confidence threshold was required for genus level assignment with the SILVA Database (Quast et al., 2013).

Table 1. $\mathrm{pH}$ results of kefir as a function of the incorporation rate (5 or $10 \%)$

\begin{tabular}{llcc}
\hline & \multicolumn{2}{c}{$\begin{array}{c}\text { Incorporation rate } \\
\text { of grains in milk }\end{array}$} \\
\cline { 2 - 3 } Kefir & $5 \%$ & $10 \%$ & $\begin{array}{c}\text { Change in } \mathrm{pH} \\
(5-10 \%)\end{array}$ \\
\hline A & 5.16 & 4.83 & 0.33 \\
$\mathrm{~B}$ & 5.14 & 4.72 & 0.42 \\
$\mathrm{C}$ & 5.22 & 4.43 & 0.79 \\
$\mathrm{D}$ & 5.27 & 4.76 & 0.51 \\
$\mathrm{E}$ & 4.57 & 4.46 & 0.11 \\
\hline
\end{tabular}




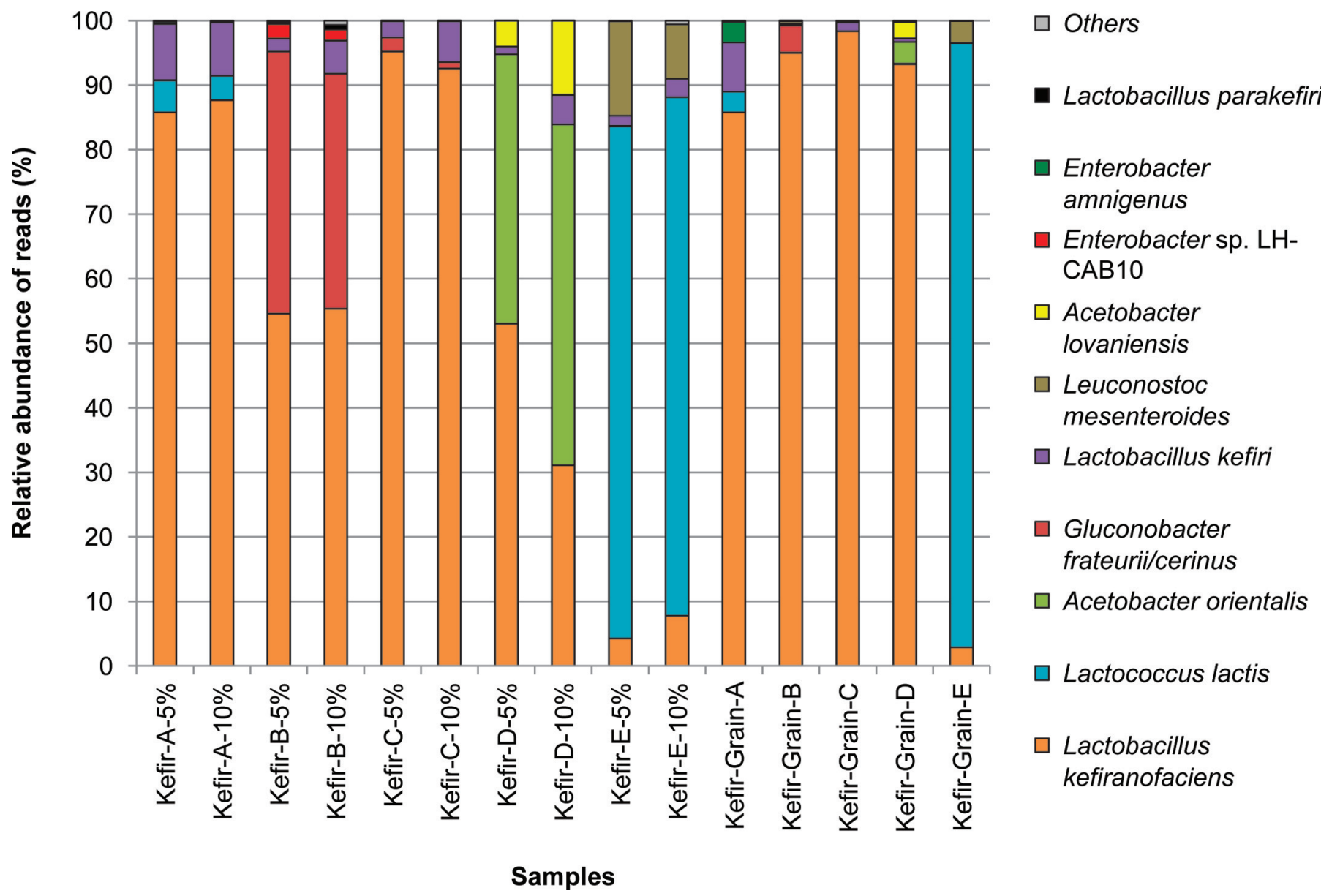

Figure 1. Relative abundance of bacterial species in samples of kefir and grains. Bar chart representing the relative abundance of bacterial species (in relation to the number of reads) detected by $16 \mathrm{~S}$ rDNA metagenetics for the 10 samples of kefir (with 5 and $10 \%$ inoculation rates) and 5 samples of grains $(\mathrm{A}-\mathrm{E})$.

The representative sequences of each OTU were compared with the National Center for Biotechnology Information $16 \mathrm{~S}$ microbial database using the Basic Local Alignment Search Tool (BLAST; Altschul et al., 1990; Gertz et al., 2006). The BLAST assignments for each OTU were assigned if the BLAST default score was above 800 . If several different bacterial species were found by BLAST for one particular OTU, all assignments were noted for this OTU. The genus assignations obtained by Mothur and BLAST were compared and noted as unclassified in the case of a mismatch. In the cases where several hits had a score above 800, the hit having the highest score was chosen for the bacterial species. Each bacterial population identified by metagenetics was analyzed as a proportion of the total bacterial flora of the sample.

The results for $16 \mathrm{~S}$ pyrosequencing are given in Figure 1, whereas the results of $26 \mathrm{~S}$ pyrosequencing (for yeasts) are shown in Figure 2. The number of reads per sample ranged between 3,111 and 5,706 for bacterial species and between 1,798 and 2,752 in the case of yeasts (Supplementary Tables S1 and S2; http:// dx.doi.org/10.3168/jds.2014-9065).

Regarding 16S pyrosequencing results, different bacterial populations were identified in the different kefirs and associated grains. Briefly, 4 families could be distinguished: kefirs $\mathrm{A}$ and $\mathrm{C}$ with a dominance of $L b$. kefiranofaciens; kefir B, also dominated by this bacterium but in association with Gluconobacter; kefir D with an equilibrium between Lb. kefiranofaciens and Acetobacter orientalis; and, finally, kefir $\mathrm{E}$ with a predominance of several OTU of Lactococcus lactis, constituting $80 \%$ of the bacterial population, and Leuconostoc mesenteroides (8 to 14\%). Regarding the results for the grains, the first 4 samples (A to D) have a strong relationship with a high proportion of Lb. kerfiranofaciens ranging between 85 and $93 \%$, whereas sample $\mathrm{E}$ differs completely, with a very high proportion of Lc. lactis of almost $95 \%$. 


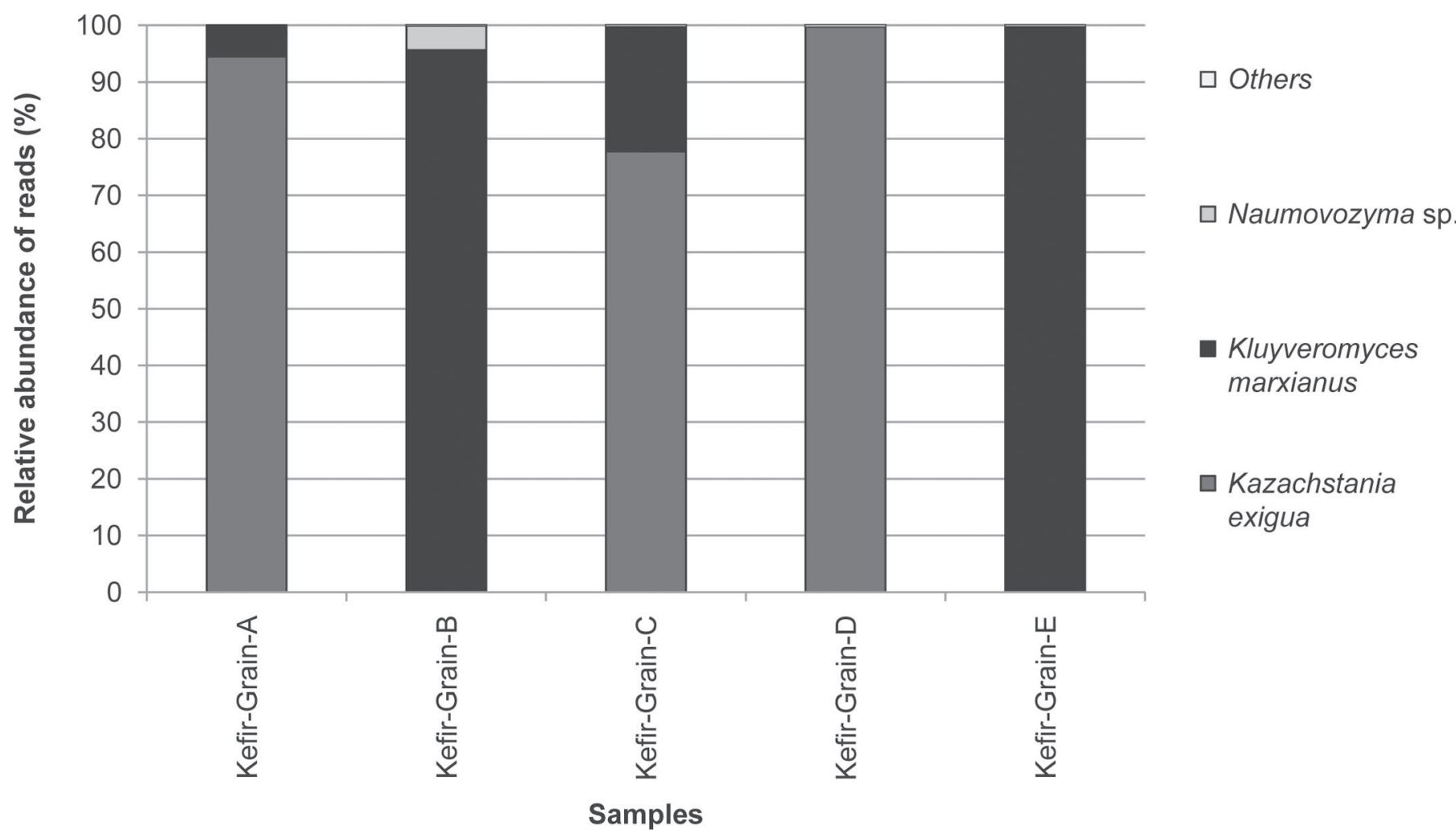

Figure 2. Relative abundance of yeasts in grains. Bar chart representing the relative abundance of yeasts (in relation to the number of reads) detected by $26 \mathrm{~S}$ rDNA metagenetics for the 5 samples of grains (kefir grains A-E).

When comparing the inoculation rates, few differences in bacterial composition were found, except in kefir D. In sample D, more Acetobacter orientalis and Acetobacter lovaniensis were recovered in the $10 \%$ kefir, whereas, at the same time, a decrease in the proportion of Lb. kefiranofaciens was observed. Concerning the results of $26 \mathrm{~S}$ metagenetics in the grains, 2 groups may be discerned: kefirs A-C-D with dominance of $K a$ zachstania khefir, and kefirs B-E, where Kluyveromyces marxianus constituted more than $95 \%$ of the yeast flora.

The decrease in $\mathrm{pH}$ observed when the grain-to-milk ratio was increased is consistent with the results reported in the literature (Garrote et al., 1998). However, those authors obtained lower $\mathrm{pH}$ levels (3.73 for $10 \%$ and 4.05 for $5 \%$ ) than those found in the present study (4.43 to 4.83). This can be explained by the longer fermentation time in the case of the study by Garrote et al. (1998) compared with our study (48 vs. $24 \mathrm{~h}$ in our experiment). Kefirs with $\mathrm{pH}$ values of 4.5 were also observed by Kök-Taş et al. (2013), which is consistent with the present study.

With the exception of kefir E, we also observed $L b$. kefiranofaciens in most kefirs. This lactobacillus was first described by Fujisawa et al. (1988). Its fermenta- tion pattern is homofermentative: it produces D-lactic acid, has a $\mathrm{G}+\mathrm{C}$ content of $35 \mathrm{~mol} \%$, and does not grow at temperatures below $15^{\circ} \mathrm{C}$. By comparing whole genome sequencing and $16 \mathrm{~S}$ pyrosequencing on 2 Turkish kefir grains, Nalbantoglu et al. (2014) also established that this bacterium constitutes the majority of the kefir microbiota. In kefir $\mathrm{E}$, we isolated mainly Lc. lactis. Other authors have rarely isolated this bacterium in kefir grains or kefir; however, by using PCR-denaturing gradient gel electrophoresis (DGGE), Chen et al. (2008) recovered it in 2 grains out of the 3 samples they analyzed, whereas Nalbantoglu et al. (2014) showed that its relative abundance was below $0.01 \%$. This contradicts Kesmen and Kacmaz (2011), who found that Lc. lactis was more prevalent in kefir than in the grains, where Lb. kefiranofaciens dominates. Acetobacter orientalis, which was most prevalent in kefir $\mathrm{D}$, is known to produce lactobionic acid that helps the absorption of calcium by the intestinal tract (Kiryu et al., 2009). This bacterium was described as being present in conjunction with Lc. lactis in Caucasus yogurt, a fermented milk product sold in Japan (Ishida et al., 2005). It has the ability to use lactose and to grow at $\mathrm{pH}$ values as low as 3.5. Lactobacillus kefiri, although 
not frequently recovered in our samples (at levels of 5 and $10 \%$ ), is described as a normal component of kefir and kefir grain (Chen et al., 2008; Miguel et al., 2010).

Gluconobacter frateurii and Gluconobacter cerinus were isolated in kefir grain B $(4.22 \%)$, and to a much lesser extent in kefir grain D $(0.021 \%)$. They were mainly encountered in kefir B at levels of between 36 and $40 \%$ and in kefir C (1 to 2\%). To our knowledge, this is the first time that this bacterium has been isolated in kefir grain, where it is more usual to recover Gluconobacter japonicus (Miguel et al., 2010; Pogačić et al., 2013). This latter is a new species of the genus Gluconobacter that produces acetic acid and belongs to Alphaproteobacteria (Malimas et al., 2009).

In relation to yeasts found in the kefir grains, Kluyveromyces marxianus was more frequently detected in kefir grains $\mathrm{B}$ and $\mathrm{E}$ and, to a lesser extent, in kefir grains $\mathrm{A}$ and $\mathrm{C}$. This yeast, which ferments lactose (Codex Alimentarius, 2003), has the potential to produce nisin when associated with Lc. lactis (Shimizu et al., 1999). This combination was encountered in grain kefir E. No explanation can be advanced as to why this yeast was not present in grain kefir D. Unfortunately, no 26S rDNA metagenetics analysis was performed on the kefir beverages to assess if the same association was also detected in the kefir beverages.

Besides this, isolated Kazachstania exigua in all the samples, except in kefir grains B and D, which is consistent with the study of Marsh et al. (2013), who detected its presence in kefir samples for the first time. The taxonomy of this yeast is quite complex, owing to the fact that the yeast Kazachstania unispora is also called Saccharomyces unisporus (Marsh et al., 2013). In kefir $\mathrm{B}$ it is worth mentioning the identification of Nauvomozyma closely related to the species Nauvomozyma castelli but sufficiently distinct. Further studies are needed to demonstrate the possible presence of a new species in this case. The genus Nauvomozyma is related to other genera, such as Kazachstania and Saccharomyces.

To correlate with conventional bacteriological methods, the yeast population and lactic acid bacteria were enumerated on yeast extract glucose chloramphenicol and on de Man, Rogosa, and Sharpe broth, respectively (data not shown). In the grains, the population of yeasts was, on average, $5 \mathrm{log} \mathrm{cfu} / \mathrm{g}$ for samples $\mathrm{A}$ to $\mathrm{D}$ and $6 \mathrm{log} \mathrm{cfu} / \mathrm{g}$ for sample E. For the lactic acid bacteria, the values were between 7 and $8 \mathrm{log} \mathrm{cfu} / \mathrm{g}$ for samples A to $\mathrm{D}$ and $4 \log \mathrm{cfu} / \mathrm{g}$ for sample $\mathrm{E}$ (data not shown). These results confirmed what is expected by the Codex Alimentarius (2003).

In conclusion, our study has proven that we can easily establish the pattern of bacterial and yeast composition of kefir and kefir grain with high-throughput sequenc- ing techniques. We can also distinguish between artisanal and industrial kefir; the latter containing a higher proportion of bacteria conventionally used in other fermented dairy products, such as Lactococcus lactis and Leuconostoc mesenteroides. One of the drawbacks of the metagenetic method is the lack of a gold standard to accurately establish the bacterial counts in the matrices analyzed. The method is not quantitative, as it is based on the sequencing of a fraction of the sample and is limited by the amount of obtained sequences. In the context of the present experiment, further studies are needed to connect the bacterial flora composition with the organoleptic characteristics of this beverage and to understand the in vivo effects on human health.

\section{REFERENCES}

Altschul, S. F., W. Gish, W. Miller, E. W. Myers, and D. J. Lipman. 1990. Basic local alignment search tool. J. Mol. Biol. 215:403-410.

Chen, H. C., S. Y. Wang, and M. J. Chen. 2008. Microbiological study of lactic acid bacteria in kefir grains by culture-dependent and culture-independent methods. Food Microbiol. 25:492-501.

Chen, Y. P., T. Y. Lee, W. S. Hong, H. H. Hsieh, and M. J. Chen. 2013. Effects of Lactobacillus kefiranofaciens M1 isolated from kefir grains on enterohemorrhagic Escherichia coli infection using mouse and intestinal cell models. J. Dairy Sci. 96:7467-7477.

Codex Alimentarius. 2003. Codex Standard for fermented milks (Codex STAN 243-2003). Codex Alimentarius, ed. http://www.codexalimentarius.org/input/download/.../CXS_243e.pdf

de Moreno de Leblanc, A., C. Matar, E. Farnworth, and G. Perdigón. 2007. Study of Immune Cells Involved in the Antitumor Effect of Kefir in a Murine Breast Cancer Model. J. Dairy Sci. 90:19201928. http://dx.doi.org/10.3168/jds.2006-079.

Fujisawa, T., S. Adachi, T. Toba, K. Arihara, and T. Mitsuoka. 1988. Lactobacillus kefiranofaciens sp. nov. isolated from kefir grains. Int. J. Syst. Bacteriol. 38:12-14.

Garrote, G. L., A. G. Abraham, and G. L. De Antoni. 1998. Characteristics of kefir prepared with different grain:milk ratios. J. Dairy Res. 65:149-154.

Gertz, E. M., Y. K. Yu, R. Agarwala, A. A. Schaffer, and S. F Altschul. 2006. Composition-based statistics and translated nucleotide searches: Improving the TBLASTN module of BLAST. BMC Biol. 4:41.

Golowczyc, M. A., M. J. Gugliada, A. Hollmann, L. Delfederico, G. L. Garrote, A. G. Abraham, L. Semorile, and G. De Antoni. 2008. Characterization of homofermentative lactobacilli isolated from kefir grains: Potential use as probiotic. J. Dairy Res. 75:211-217.

Guzel-Seydim, Z. B., T. Kok-Tas, A. K. Greene, and A. C. Seydim. 2011. Review: Functional properties of kefir. Crit. Rev. Food Sci. Nutr. 51:261-268.

Hamet, M. F., A. Londero, M. Medrano, E. Vercammen, K. Van Hoorde, G. L. Garrote, G. Huys, P. Vandamme, and A. G. Abraham. 2013. Application of culture-dependent and culture-independent methods for the identification of Lactobacillus kefiranofaciens in microbial consortia present in kefir grains. Food Microbiol. $36: 327-334$

Hertzler, S. R., and S. M. Clancy. 2003. Kefir improves lactose digestion and tolerance in adults with lactose maldigestion. J. Am. Diet. Assoc. 103:582-587.

Ishida, T., A. Yokota, Y. Umezawa, T. Toda, and K. Yamada. 2005. Identification and characterization of lactococcal and Acetobacter strains isolated from traditional Caucasian fermented milk. J. Nutr. Sci. Vitaminol. (Tokyo) 51:187-193.

Kesmen, Z., and N. Kacmaz. 2011. Determination of lactic microflora of kefir grains and kefir beverage by using culture-dependent and culture-independent methods. J. Food Sci. 76:M276-M283. 
Kiryu, T., T. Kiso, H. Nakano, K. Ooe, T. Kimura, and H. Murakami. 2009. Involvement of Acetobacter orientalis in the production of lactobionic acid in Caucasian yogurt ("Caspian Sea yogurt") in Japan. J. Dairy Sci. 92:25-34.

Kök-Taş, T., A. C. Seydim, B. Özer, and Z. B. Guzel-Seydim. 2013. Effects of different fermentation parameters on quality characteristics of kefir. J. Dairy Sci. 96:780-789.

Kurtzman, C. P., and C. J. Robnett. 1997. Identification of clinically important ascomycetous yeasts based on nucleotide divergence in the $5^{\prime}$ end of the large-subunit (26S) ribosomal DNA gene. J. Clin. Microbiol. 35:1216-1223.

Lopitz-Otsoa, F., A. Rementeria, N. Elguezabal, and J. Garaizar. 2006. Kefir: A symbiotic yeasts-bacteria community with alleged healthy capabilities. Rev. Iberoam. Micol. 23:67-74.

Malimas, T., P. Yukphan, M. Takahashi, Y. Muramatsu, M. Kaneyasu, W. Potacharoen, S. Tanasupawat, Y. Nakagawa, M. Tanticharoen, and Y. Yamada. 2009. Gluconobacter japonicus sp. nov., an acetic acid bacterium in the Alphaproteobacteria. Int. J. Syst. Evol. Microbiol. 59:466-471.

Margulies, M., M. Egholm, W. E. Altman, S. Attiya, J. S. Bader, L. A. Bemben, J. Berka, M. S. Braverman, Y. J. Chen, Z. Chen, S. B. Dewell, L. Du, J. M. Fierro, X. V. Gomes, B. C. Godwin, W. He, S. Helgesen, C. H. Ho, G. P. Irzyk, S. C. Jando, M. L. Alenquer, T. P. Jarvie, K. B. Jirage, J. B. Kim, J. R. Knight, J. R. Lanza, J. H. Leamon, S. M. Lefkowitz, M. Lei, J. Li, K. L. Lohman, H. Lu, V. B. Makhijani, K. E. McDade, M. P. McKenna, E. W. Myers, E. Nickerson, J. R. Nobile, R. Plant, B. P. Puc, M. T. Ronan, G. T. Roth, G. J. Sarkis, J. F. Simons, J. W. Simpson, M. Srinivasan, K. R. Tartaro, A. Tomasz, K. A. Vogt, G. A. Volkmer, S. H. Wang, Y. Wang, M. P. Weiner, P. Yu, R. F. Begley, and J. M. Rothberg. 2005. Genome sequencing in microfabricated high-density picolitre reactors. Nature 437:376-380.
Marsh, A. J., O. O'Sullivan, C. Hill, R. P. Ross, and P. D. Cotter. 2013. Sequence-based analysis of the microbial composition of water kefir from multiple sources. FEMS Microbiol. Lett. 348:79-85.

Miguel, M. G. D. C. P., P. G. Cardoso, L. D. A. Lago, and R. F. Schwan. 2010. Diversity of bacteria present in milk kefir grains using culture-dependent and culture-independent methods. Food Res. Int. 43:1523-1528.

Nalbantoglu, U., A. Cakar, H. Dogan, N. Abaci, D. Ustek, K. Sayood, and H. Can. 2014. Metagenomic analysis of the microbial community in kefir grains. Food Microbiol. 41:42-51.

Otles, S., and O. Cagindi. 2003. Kefir: A probiotic dairy-composition, nutritional and therapeutic aspects. Pakistan J. Nutr. 2:54-59.

Pogačić, T., S. Šinko, Š. Zamberlin, and D. Samaržija. 2013. Microbiota of kefir grains. Mljekarstvo 63:3-14.

Quast, C., E. Pruesse, P. Yilmaz, J. Gerken, T. Schweer, P. Yarza, J. Peplies, and F. O. Glöckner. 2013. The SILVA ribosomal RNA gene database project: Improved data processing and web-based tools. Nucleic Acids Res. 41:D590-D596.

Rodrigues, K. L., L. R. G. Caputo, J. C. T. Carvalho, J. Evangelista, and J. M. Schneedorf. 2005. Antimicrobial and healing activity of kefir and kefiran extract. Int. J. Antimicrob. Agents 25:404-408.

Santos, A., M. San Mauro, A. Sanchez, J. M. Torres, and D. Marquina. 2003. The antimicrobial properties of different strains of Lactobacillus spp. isolated from kefir. Syst. Appl. Microbiol. 26:434-437.

Shimizu, H., T. Mizuguchi, E. Tanaka, and S. Shioya. 1999. Nisin production by a mixed-culture system consisting of Lactococcus lactis and Kluyveromyces marxianus. Appl. Environ. Microbiol. 65:3134-3141.

Zheng, Y., Y. Lu, J. Wang, L. Yang, C. Pan, and Y. Huang. 2013. Probiotic properties of lactobacillus strains isolated from tibetan kefir grains. PLoS ONE 8:e69868. 